\title{
Study of Arabian Gulf Consumers Perception Towards Implementing Environmental Measurements in GCC: A Basis for Strategies Enhancement in Organisational Effectiveness During Covid 19
}

\author{
Hosam Azat Elsaman ${ }^{1 *}$ and Liza Gernal ${ }^{2}$ \\ ${ }^{1}$ Catholic university of Murcia (UCAM), Spain \\ ${ }^{2}$ Westford University College, UAE
}

\begin{abstract}
Business sustainability and stakeholder theory can be defined as management and coordination between social and environmental demands with business financial profit in a protocol of responsibility and success relation. (Rouse, 2013). The paper's methodology is based on examining the theory of stakeholders and triple bottom lines business models. Researchers followed deductive approaches and descriptive correlation analysis design the Excel statistics tools such as regression analysis and ANOVA test applied while the sampling techniques followed snowball sampling model, by conducting two surveys first one at precovid and second at during pandemic with a total number of 340 respondents. Quantitative method was done using survey monkey to gather the information from the respondents. The main results of this research concluded that the significant positive relationship between both organization environmental measurements and strategies and performance of organization and increasing the consumer's loyalty. The consumer's feedback varies from different variables such as ethnicity, gender, age, and regional locations, producing and promoting environmentally friendly products. Meantime, the paper spotted the changes in consumers' perception of economic subjects before and after the Covid-19 pandemic outbreak. The results clearly show a greater understanding between the public's environmental problems and their links to economic and social factors (Elsaman, 2020). They also show that people are worried about environmental deterioration and resource depletion and that they generally are happy with the government response. On the other hand, the survey indicates that the public is overwhelmingly ready to encourage positive change by encouraging stricter environmental protection and natural resource conservation legislation and taking personal action.
\end{abstract}

Keywords: Strategy, Stakeholders, Covid-19, ecological measurement. 


\section{Introduction}

Each organization at this time of Covid 19 faced a big challenge that may affect the efficiency and productivity of the whole organization. Organizations thrive to identify the various issues they have in the functions and operations within, then assess the root causes of the issues and work on finding a resolution to eliminate the challenge and enhance the processes internally.

The concept of environmental responsibility should be considered aside from economic and legal obligations for any corporate. The topic of environmental measurements is high demand trend nowadays. The research appraised the link between environmental measurements and strategies and organizational growth before and after COVID-19 pandemic outbreak in the region of Arabian gulf in industrial lubricants industry, also detect to what extent adopting triple bottom lines and stakeholder theory can enhance the corporates and business leverage.

\section{Stakeholder theory.}

Stakeholder theory concern with organizational management and business protocol of ethics in organization by applying values in process of organization management. Edward freeman definition for stakeholders: Any individual or group that may be interested in/or affected by the plans and activities of an organization" (Freeman, 2007). It means Employees, shareholders, Suppliers, Competitors, Customers, Domestic environment. On the other hand, Clarkson gives more particular definition and classification for stakeholders. Voluntary, Involuntary stakeholders. Legitimacy. (Clarkson, 1994). Voluntary: stands for stakeholders who decide to contribute or play a role in corporate decision making for example management, staff, social groups, and shareholders. Involuntary: represent the stakeholders that do not decide to directly contribute to corporate decisions making but become involved for any reason. That could be key account customers. vendors, government, environment, and local society. They cannot reduce in short or medium time. Legal factor: those factors or principles with direct commercial or economic relationship with a company, such as customers and suppliers. their reviews and feedback should be considered before deciding.

For applying this process, the company should organize and determine the stakeholders who are necessary for achieving the targets and maintain the

a long-term successful relationship with them. It means to control and monitoring of an organization's goals by satisfying all groups or stakeholders who have a direct stake in company and support the process of achieving its goals. (Zahra, 2011). This mechanism should consider the social and psychological contracts of company not only business contracts. After identifying the stakeholders theory, we should go for Analysis of Stakeholder analysis is a process of detecting the individuals or groups who will affect or be affected by the corporate activities and approaching its goals, then and classify them according to their importance. The benefits of stakeholder analysis allow more successful communicating frequently with corporate stakeholders will help them to fully understand what is going on with the process and how they can support the process. 


\section{Three bottom line theory :}

The triple bottom line (TBL) is a system or theory that explains the organization should focus on social and environmental goals just as they do on profits. The TBL that instead of one bottom line which is profit, there should be three bottom lines or 3 P's: profit, people, and planet John (Krane, 2018). Elkington, 1994 defined "triple bottom line" as the idea was that we can manage a company in a way that not only earns financial profits, but which also improves people's lives and the planet. Furthermore, the concept of Sustainability and business performance and to what extent the sustainability correlated with approaching the business and stakeholders values in contemporary business nowadays.

The Triple Bottom Line gives more awareness for ethical and environmental aspects. The financial bottom line is the factor of profit for any company, however, for the TBL theory, it should be beyond profit including environmental and social factors. therefore, the company with a concern of profit only definitely will lose its value or momentum socially or with domestic environment. it cannot see the whole picture and full feedback.

According to the three bottom lines theory company should focus on 3 lines at the same time. Profit: The definition of profit refers to measure of corporate benefits range and the profit and loss (P\&L) calculation. People, Measures how socially responsible an organization has been throughout its operations. The Planet, Measures how environmentally responsible. By focusing on these three interrelated elements, triple-bottom-line reporting can be an important tool to support a firm's sustainability goals (Singh, 2013)

\section{Environmental strategy}

Environmental strategies are the best approach that mainly focused on environmental safety and performing different enterprise activities. It consists of production, modification in packaging, and another type of green advertisement. In order to engage with the client practices and actions regarding environment friendly, the oil-based lubricants industry has attracted for effects of business operations in the environment, especially when the inadequate response of lubricant industry and increase the environmental issues (Arseculeratne, 2014)Therefore, it has raised the concern towards the commitment to sustainable development. In GCC, many energy companies are instructed to emphasize ecological footprint, which will try to mitigate sustainable development. The economic development within industrial lubricants sector is crucial for managing and controlling overall business opportunities.

The environmental policy consists of a broad variety of business processes aimed at satisfying customer needs while also minimizing negative effects on the natural environment. Designing and executing a green marketing plan is a challenging challenge for the oil industry because it necessitates the use of sufficient and readily available tools, priorities, and objectives. In order to improve the profitability of the organization.

Many energy sources, such as petroleum products, continue to play an important role in the lubricant industry. Lately, there are plenty of diverse interests between oil and gas exploration, 
which could be increasing the pressure to reduce the environmental effects caused by energy production and consumption.

Integrating Eco-friendly marketing strategy will improve opportunities for the company because the customer will like the latest green oil item and will be mindful of the natural environment. As a result, the oil lubricant industry has altered its business practices while employing green marketing tactics. (Jones, Jain, 2019).

Cultural awareness plays an essential role in customer feedback to try or applying a new concept. GCC countries wealth and legal structure consider factors led to creating more challenges on how to convince the end-user to shift from conventional product to new green technology product. (Bart Frijnsa, 2013).

Oil industry is vital lifeline of global economy in GCC region, which contributes to $57 \%$ share in energy consumption, it has been suggested by experts to measure the emission from extraction as well as transformation. It is a major energy consumer which met by use of fossil fuels. As per analysis, it has found that $6.9 \%$ of total energy produced by oil industry. (Wooders, Zinecker, Steenblik, 2019).

Oil and gas industry can transform the operation and function through increased energy efficiency and use of sustainable products, this strategy considers as an alternative method for increasing profitability and productivity in global marketplace. (Nunes, Causer, Ciolkosz ,2020)

Moreover, lubricants industry utilized a smart energy strategy to support reducing carbon emission, this strategy is the most suitable for organizations to handle the overall business operations and functions. The expert knows about energy improvement while increasing opportunities and reduce the rate of carbon emissions. In this way, it becomes easier to measure energy efficiency such as selecting the appropriate right lubrication items that directly give positive impact on environmental subjects. Thus, it allows for the organization to maintain safety and ecological condition. To improve the work environment and handle the business challenges professional manner. (Vogl, Weiss, Helu,2019).

Recently, there is high demand in reducing the energy and power using in machinery and automotive engines in order to decrease the dangerous emissions and control the negative impacts on environment. (Margaret, 2013).

\section{Organisation effectivness \& effeciency.}

Organizational effectiveness described as the ability of an agency, community, or business to accomplish its goals. Organizational efficiency refers to how a company achieves its inventory quotas, how much waste it creates, and how productive its processes are. That technique focuses on increasing the overall performance of a business operation (Northouse, 2019).

Organizational efficiency is all about deciding how to be more efficient by using less resources, less time, and less money to accomplish the same goal. Organizational efficiency is calculated in terms of time, commitment, and performance. When attempting to assess performance, the most important question to ask is: "How can I achieve the best results while spending the least amount of expenses . Organizational Efficiency is the ability to use effectiveness to measure nearly any process that runs your company. However, efficiency is often about the financial 
costs and outcomes of doing things. When it comes to calculating the return on investment in marketing and sales, efficiency is particularly critical. As a company owner, you most definitely do not have unlimited resources.

Organizational performance is described as an organization's actual production or results as measured against its expected outputs. Financial efficiency, product market performance, and shareholder return are all components of organizational performance. If the long- and shortterm objectives have been identified, it is time to evaluate organizational effectiveness in relation to those goals.

\section{Research objectives:}

1- Examine the changes in consumer awareness toward environmental topic in the period before and after the COVID-19 pandemic outbreak.

2- Evaluate to what extent the consequences of implementing environmental strategies could enhance the organizational output.

\section{Research Philosophy and methodology}

Research philosophy and methodology consider a vital section of study, it is concerned about how information should be gathered and analysed in a research project. Research philosophy provides the base of research which involves the choice of research strategy, identify the problem, gathering data, analysis, then finding and results (Saunders, et al., 2009). The theory of research makes it easier to access reality by constructing social infrastructure such as instruments, language, and shared symbolic meanings. It is possible to adequately understand the positive concept of philosophy based on the social world. The researcher analyses the objective and distances it from personal attitudes and works individually (Žukauskas,2018). In this research, the positivism philosophy used to interpret the research elements and deductive approaches used to examine the theory of Stakeholders and triple bottom line concepts. Often this theory is utilized to integrate a study project with the interest of the human being. Positivism focusses on facts and knowledge collected from quantitative surveys then going to statistical analyses. the study adopted deductive approaches and descriptive correlation analysis design, the Excel statistics tools such as regression analysis and Inova test applied while the sampling techniques followed snowball sampling model, by conducting two surveys first one at February 2020 and second at February 2021 with a total number of 340 respondents. Through quantitative method particularly through survey (Collins, 2010). 


\section{Research Finding \& Results}

The first survey in February 2020 results as below :

Fig 1: Respondents age and the feedback toward enviromental strategies in industrial lubricants GCC market.

\begin{tabular}{|c|c|c|c|c|c|c|c|c|c|c|c|c|c|c|}
\hline \multirow{3}{*}{ Very positive } & \multicolumn{14}{|c|}{ Q2_What is your age? } \\
\hline & \multicolumn{2}{|c|}{$\begin{array}{c}17 \text { or } \\
\text { younger }\end{array}$} & \multicolumn{2}{|c|}{$18-20$} & \multicolumn{2}{|c|}{$21-29$} & \multicolumn{2}{|c|}{ 30-39 } & \multicolumn{2}{|c|}{$40-49$} & \multicolumn{2}{|c|}{$50-59$} & \multicolumn{2}{|c|}{60 or older } \\
\hline & 0 & $0.0 \%$ & 0 & $0.0 \%$ & 10 & $47.6 \%$ & 25 & $37.9 \%$ & 12 & $40.0 \%$ & 2 & $40.0 \%$ & 0 & $0.0 \%$ \\
\hline Somewhat positive & 0 & $0.0 \%$ & 1 & $100.0 \%$ & 5 & $23.8 \%$ & 21 & $31.8 \%$ & 10 & $33.3 \%$ & 0 & $0.0 \%$ & 0 & $0.0 \%$ \\
\hline Neutral & 0 & $0.0 \%$ & 0 & $0.0 \%$ & 6 & $28.6 \%$ & 19 & $28.8 \%$ & 8 & $26.7 \%$ & 3 & $60.0 \%$ & 0 & $0.0 \%$ \\
\hline Somewhat negative & 0 & $0.0 \%$ & 0 & $0.0 \%$ & 0 & $0.0 \%$ & 1 & $1.5 \%$ & 0 & $0.0 \%$ & 0 & $0.0 \%$ & 0 & $0.0 \%$ \\
\hline Very negative & 0 & $0.0 \%$ & 0 & $0.0 \%$ & 0 & $0.0 \%$ & 0 & $0.0 \%$ & 0 & $0.0 \%$ & 0 & $0.0 \%$ & 0 & $0.0 \%$ \\
\hline Total & 0 & $0.0 \%$ & 1 & $100.0 \%$ & 21 & $100.0 \%$ & 66 & $100.0 \%$ & 30 & $100.0 \%$ & 5 & $100.0 \%$ & 0 & $0.0 \%$ \\
\hline
\end{tabular}

Fig 1. shows the Percentage charts between respondendts age and feedback towards applying eco-friendly measurment before Covid 19 outbreak. $60 \%$ from consumers above 50 years old were neutral as the first reaction, they did not show any interest for the enviromental concept, against $40 \%$ of them were very positive. $47.6 \%$ from youth people (21-29 yrs.) are very positive from the first reaction, against $28.6 \%$ were Neutral. In same context, the results identifiy the opinion and point of view for customer toward the new ecological concept. This analysis gives in-depth data will be very useful in the segmentation process in enviromental strategic planing.

Fig 2: Relation between gender and the awarnes for new enviromental technology

\begin{tabular}{|c|c|c|c|c|c|c|}
\hline \multirow[b]{2}{*}{ Description } & \multicolumn{2}{|l|}{ Male } & \multicolumn{2}{|c|}{ Female } & \multicolumn{2}{|l|}{ Total } \\
\hline & Count & $\begin{array}{l}\text { Column N } \\
\%\end{array}$ & Count & $\begin{array}{l}\text { Column N } \\
\%\end{array}$ & Count & $\begin{array}{l}\text { Column N } \\
\%\end{array}$ \\
\hline Eco friendly concept & 29 & $32.60 \%$ & 18 & $56.30 \%$ & 47 & $38.80 \%$ \\
\hline $\begin{array}{l}\text { Extra benefits ,Fuel } \\
\text { saving , Motor } \\
\text { performance } \\
\text { improver }\end{array}$ & 45 & $50.60 \%$ & 11 & $34.40 \%$ & 56 & $46.30 \%$ \\
\hline $\begin{array}{l}\text { Normal price or } \\
\text { lightly higher }\end{array}$ & 15 & $16.90 \%$ & 3 & $9.40 \%$ & 18 & $14.90 \%$ \\
\hline $\begin{array}{l}\text { Other } \\
\text { specify) }\end{array}$ & 0 & $0.00 \%$ & 0 & $0.00 \%$ & 0 & $0.00 \%$ \\
\hline Total & 89 & $100.00 \%$ & 32 & $100.00 \%$ & 121 & $100.00 \%$ \\
\hline
\end{tabular}

"50.6\% males thinking that Extra benfits,Fuel saving, Motor performance improver are on atop of mind witout any consideration for enviromental topic they like most about $46.3 \%$ from 
sample size 121 respondents saying the same. In contast way female percentage showed more awarness towards enviromental topic more than materilastic benfits.

\section{The second survey in February 2021 results as below :}

Fig 3: Regression analysis, ANOVA test and correlational coefficient for 2 variables consumer awareness and organization environmental strategies.

\begin{tabular}{|l|r|}
\hline \multicolumn{2}{|l|}{ SUMMARY OUTPUT } \\
\hline Regression Statistics \\
\hline Multiple R & 1 \\
\hline R Square & 1 \\
\hline Adjusted R Square & 1 \\
\hline Standard Error & $1.34475 \mathrm{E}-16$ \\
\hline Observations & 155 \\
\hline
\end{tabular}

\begin{tabular}{|c|c|c|c|c|c|}
\hline ANOVA & & & & & \\
\hline & $d f$ & SS & $M S$ & $F$ & Significance $F$ \\
\hline Regression & 4 & 17.52177419 & 4.380444 & $2.42233 \mathrm{E}+32$ & 0 \\
\hline Residual & 150 & $2.71254 \mathrm{E}-30$ & $1.81 \mathrm{E}-32$ & & \\
\hline Total & 154 & 17.52177419 & & & \\
\hline
\end{tabular}

\begin{tabular}{|l|r|r|r|r|}
\hline & Coefficients & Standard Error & \multicolumn{1}{c}{ Stat } & \multicolumn{1}{c|}{$P$-value } \\
\hline Intercept & $-3.33067 \mathrm{E}-16$ & $8.46245 \mathrm{E}-17$ & -3.93582 & 0.000126497 \\
\hline PROMOTE GREEN & 0.25 & $1.98612 \mathrm{E}-17$ & $1.26 \mathrm{E}+16$ & 0 \\
\hline CONSATTRACT & 0.25 & $1.9536 \mathrm{E}-17$ & $1.28 \mathrm{E}+16$ & 0 \\
\hline SHAREHOLDERS & 0.25 & $1.25662 \mathrm{E}-17$ & $1.99 \mathrm{E}+16$ & 0 \\
\hline GREENADSCAMPA & 0.25 & $2.00305 \mathrm{E}-17$ & $1.25 \mathrm{E}+16$ & 0 \\
\hline
\end{tabular}

The findings effectively demonstrate a better view of the population respondents towards environmental issues and their connections to economic and social considerations.

The statical analysis highlighted significant relation between research variables in positive way. result also demonstrate that people are concerned about environmental degradation and resource depletion, and that they are largely satisfied with the organisation environmental measurements. From the other hand, the study findings indicate that the community is largely essential to enhance social reform by pushing for stronger environmental preservation and natural resource management laws, as well as taking personal action. Furthermore, the study discovered that customers are more responsive to sustainable and environment businesses, which boost the organization's reputation and definitely raise profits. 


\section{Conclusion}

It demonstrates that the most of GCC residents opinions and awareness towards the environmental concept is varied from the situation before and after the covid 19 outbreak. Recently the major of respondents are already aware and agreeable that adopting environmentally strategies in the field of lubricant in GCC by using more eco-friendly products and give extra considerations for the stakeholders and triple bottom lines concept add competitive advantage for the business in the current pandemic situation.

Previously, individuals were unconcerned about the effects of environmental protection, understanding, and practice. However, as a result of educational campaigns available in the area, the understanding of the product or organization that uses phrases on promotional materials such as avoid environmental contamination, stay healthy at home, and we care about you and your family's health has increased.

GCC countries continue to face a broad range of environmental risks, both persistent and increasing. Output and consumption models, which are the root causes of environmental problems, continue to attract a lot of focus. It is strongly suggested that the GCC countries' Ministries of Environment spread the benefits of green marketing across the region in order to conserve the region's limited resources( Elsaman, Gernal, 2021).

\section{Acknowledgment}

The researchers highly appreciate the real support offered by management of oil \& gas companies by sharing the new technology data which serve as the research objectives.

\section{Bibliography}

Agyeman, C. M., 2014. Consumers' buying behavior towards green products: An exploratory study. International Journal of Management Research and Business Strategy, Volume 3, pp. 189-197.

Arseculeratne, D. \&. Y. R., 2014. How green marketing can create a sustainable competitive advantage for a business. International business research, Volume 7, pp. 130-137.

Bart Frijnsa, A. G. T. L. a. A. T.-R., 2013. Uncertainty avoidance, risk tolerance and corporate takeover decisions.. Journal of Banking \& Finance, 37(7), pp. 245-247. 
Clarkson, M., 1994. A Risk Based Model of Stakeholders Theory. Toronto, Center for corporate social Performance\&Ethics university of Toronto.

Collins, H., 2010. Creative Research: The Theory and Practice of Research for the Creative Industries. In: s.1.:AVA publications , p. 38.

Creswell, J. a. C. J., 2017. Research design: Qualitative, quantitative, and mixed methods approaches. s.l.:Sage publications..

Elsaman, H. a. S. R., 2020. The Green Marketing Strategy in Selected Lubricant Sector in the Kingdom of Saudi Arabia and Its Implications to Corporate Organizational Growth.. Berlin, Dpublication.

Freeman, 2007. Strategic Managment. In: stakeholders approch. Boston: Pitman.

Hosam Elsaman, L. G., 2021. A Descriptive Study of United Arab Emirates Buying Behaviour and Green Marketing Strategies during the COVID-19 Outbreak in Oil \& Gas Lubricants Industry. Dubai, Skyline university.

James, 2019. HR Management and organisational structure. International Journal of Management, 7(2), p. 56.

Jones, E. ,. J. S., 2019. Evaluating the Impact of Sustainability and Pipeline Quality on the Global Crude Oil Supply Chain. Supply Chain Engineering and Logistics Handbook: Inventory and Production Control, p. 49.

Kinoti, M. W., 2011. a conceptual paper.Green marketing intervention strategies and sustainable development. International Journal of Business and Social Science, pp. p2-23..

Krane, J., 2018. Climate Strategy for Producer Countries: The Case of Saudi Arabia, s.1.: s.n. Mallin, 2015. Corporate Governrance. In: s.1.:5th Ed,Oxford.

mangment, S. G. f. P., 2006. Survival Guide for Project Management. [Online] Available at: Survival Guide for Project Management [Accessed 2006].

Margaret, R., 2013. business sustainability definition, s.1.: s.n.

Northouse, P. G., 2019. Leadership Theory and Practice. Eight ed. London: Sage.

Nunes, L. C. T. a. C. D., 2020. Biomass for energy: A review on supply chain management models. Renewable and Sustainable Energy Reviews., Volume 120.

Pranas Žukauskas, J. V. a. R. A., 2018. Philosophy and Paradigm of Scientific Research, Management Culture and Corporate Social Responsibility, s.l.: s.n.

Rjeshkumar, M., 2012. Naamex Internationa Journal of Management Research,. [Online] Available at: 19. Rajeshkumar, M. L. (2012). An overview of green marketing. http://www.namexijmr.com/pdf/archives_jan_june_2

012/namex\%20ijmr\%20\%20abstract\%20and\%20pap er \%2014.pdf

Rouse, M., 2013. business sustainability definition, s.1.: s.n.

Singh, J. K., 2013. Journal of Indian Research. Journal of Indian Research (ISSN: 2321-4155) Vol.1, No.4, October-December, 2013, 105111, Vol.1, No.4((ISSN: 2321-4155)), pp. 105,111. 


\section{World Conference on MANAGEMENT, BUSINESS and ECONOMICS}

Steenblik, R. \&. W. P. \&. Z. A., 2019. Measuring Fossil Fuel Subsidies in the Context of the Sustainable Development Goals, s.1.: United nation enviromental programme.

Suki, N. M., 2013. Green Awareness effects on consumer's purchasing decision. Some insights from Malaysia. Green awareness effect, Volume 9, pp. 50-63.

Venable, J. P.-H. J. a. B. R., 2017. Choosing a Design Science Research Methodology. , University of Tasman: In 28th Australasian Conference on Information SystemsI. EEE/ACIS International Conference on Computer and Information Science.

Vogl, G. W. B. a. H. M., 2019. A review of diagnostic and prognostic capabilities and best practices for manufacturing. Journal of Intelligent Manufacturing, 30(1), pp. 79-95.

Walker, K. Z. Z. a. N. N., 2019. corporate social irresponsibility and firm performance in coordinated market economies and Liberal market economies. British Journal of Management, 30(1), p. 1.

Wilson, J., 2104. Essentials of business research: A guide to doing your research project. s.l.: Sage.

Wright, K., 2005. Researching Internet-based populations: Advantages and disadvantages of online survey research, online questionnaire authoring software packages, and web survey services.. Journal of computer-mediated communication, 10(3), p. 10.

Xiaojin, W. \&. J. H., 2006. The relationships between key stakeholders' project performance and project success: Perceptions of Chinese construction supervising engineers. International Journal of Project Management, 24(10.1016/j.ijprom), pp. 253-260.

Zahra, A., 2011. rethinking Regional Tourism :The Principle of Subsidiarity,. Journal of Sustainable Tourism, pp. 535-552, Vol19.

Zhang, Q. O. B. a. L. B., 2019. Drivers, motivations, and barriers to the implementation of corporate social responsibility practices by construction enterprises. Journal of cleaner production, Volume 210, pp. 563-584.

Zhu, Q. Z. F. a. Z. P., 2019. The role of innovation for performance improvement through corporate social responsibility practices among small and medium- sized suppliers in China. Corporate Social Responsibility and Environmental Managemen, 26(2), pp. 341-350. 